\title{
Tracing current-voltage curve of solar panel Based on LabVIEW Arduino Interfacing
}

\author{
Arar HEMZA ${ }^{1}$, Haouam ABDESLAM ${ }^{1}$, Chenni RACHID $^{1}$, Marcel PASQUINELLI ${ }^{2}$, Damien BARAKEL ${ }^{2}$ \\ ${ }^{1}$ Department of Electronic, Faculty of Science and Technology \\ Constantine1 University, Constantine, Algeria \\ ${ }^{2}$ Institute Microelectronics Materials Nanosciences of Provence \\ Aix Marseille University, Marseille, France \\ rachid.chenni@gmx.fr \\ (Geliş/Received: 06.01.2015; Kabul/Accepted: 29.05.2015) \\ DOI: $10.17671 / \mathrm{btd} .39450$
}

\begin{abstract}
This study describes a low cost system to measure current and power-voltage characteristics of photovoltaic (PV) silicon solar panel under natural conditions based on LabVIEW software. The desired parameters of PV panel including fill factor, max power, short-circuit current, open-circuit voltage are calculated. The characteristics of the solar panel have been drawn quickly using the MOSFET as an electronic load, which is controlled by means of a suitable gate-source voltage. The new development of this work includes the Arduino to acquire the values of current and voltage from the solar panel under test and transfer it to a supervisory computer. All details of the electronic circuit are shown in this paper and experimental results obtained are presented.
\end{abstract}

Keywords - photovoltaic (PV), LabVIEW, Arduino, current and power-voltage characteristics, MOSFET as an electronic load.

\section{INTRODUCTION}

Electrical power is currently required of our globe. Renewable energy resources will be increasingly important part in the production of electricity, in this context, Photovoltaic systems are the most resources used in the world wide (solar electric power systems has grown gradually from last (10-15) years) [1]. In photovoltaic field, the solar cell allows to obtaining the electricity directly by converting sunlight into electricity available and adaptable to our needs.

However, the lifetime of solar panel degrades with the progress of year due to the environment conditions, which effects on its fundamental parameters [2], to estimate and evaluate the performance of photovoltaic modules or arrays such as fill factor $(\mathrm{FF})$, open-circuit voltage $\left(V_{o c}\right)$, short circuit current $\left(I_{s c}\right)$ and maximum power $\left(P_{m p}\right)$, the characteristic current-voltage (I-V) is necessary [3].

In standard test condition (STC: $1000 \mathrm{~W} / \mathrm{m}^{2}$ of irradiance, $25^{\circ} \mathrm{C}$ cell temperature and air mass 1.5$)$, the characteristic (I-V) and parameters of PV modules are provided by the Manufacturers. However, the outdoor operating conditions are different from the STC. As we know, that the study of the behavior and performance of photovoltaic modules is done through its I-V characteristic, for this reason, we set up a data acquisition system to trace the current-voltage and power-voltage characteristics under normal operating conditions of the PV panel.

This system can plot the curve of the characteristics of solar cell using an electronic load, in photovoltaic field; we can test the PV module with different types of charge, in [4] they have explained that with a simple variable resistor (rheostat) we can obtain each point of the I-V curve by varying the resistor from zero to infinity. The accuracy of this type of load is low, because the change of charge can be done manually. In addition, they have reported that we can get all points of the I-V curve from short circuit to open circuit of solar panel with Bipolar Power Amplifier, but the disadvantage of this method is its higher losses of power.

In $[5,6,7,8]$ they have done their electronic circuit to achieve the characteristics of PV module using a power Metal-Oxide-Semiconductor Field-Effect Transistor (MOSFET) as an electronic load; in its region active, we can get the output voltage terminal from open circuit to zero and the output current array from zero to short circuit. The big advantage of this method is the fast test of the PV module. The quick scanning of all values of this load makes the measurements performance of $\mathrm{PV}$ modules very accurate.

In this paper, we utilize virtual instrumental LabVIEW (contraction of Laboratory Virtual Instrument Engineering Workbench) to make platform between the computer and the instrument in order to display the characteristics curve

Current-voltage of the PV panel [9]. This work combined however, the Arduino board with LabVIEW, which allows the user to make graphically the dealt of the measurements arrays in the computer.

\section{MATHEMATICAL MODEL OF SOLAR CELL}

To optimizing the performance of the photovoltaic (PV) module, we should analyze the behavior of its characteristic I-V by making the simulation of the equivalent circuit (Fig. 1) of solar cell. 


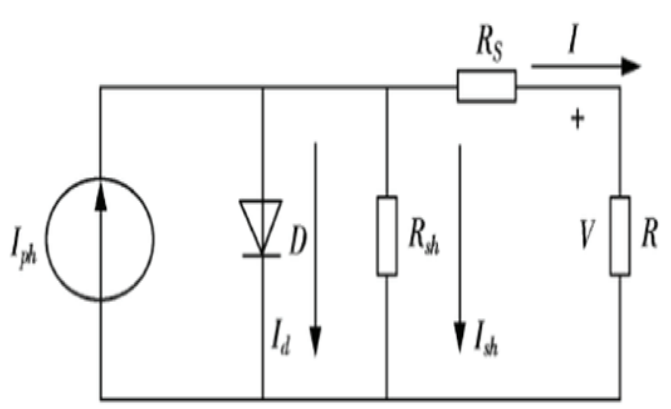

Figure 1. Solar cell model [9]

Because its simplicity and precision in mathematical calculation, the so called one diode model that is illustrated above is the most equivalent circuit utilized in the modeling of PV panel [8-9]. The solar cell is a P$\mathrm{N}$ junction that can absorb the radiation to generate the pair electron-hole, which results a current due to electromagnetic field in the depletion region. The model consist a source current $I_{p h}$ in parallel with a diode, a series resistance $R_{S}$ and parallel resistance $R_{P}$. Using the node law of Kirchhoff,

$$
I=I_{p h}-I_{d}-I_{s h}
$$

The equation relating the current delivered by a PV module consisting of $\mathrm{n}$ series solar cells and the voltage at its terminals is given in Eq. (2),

$$
I=I_{p h}-I_{0}\left[\exp \left(\frac{\left(V+I R_{S}\right) q}{N K T_{C}}\right)-1\right]-\frac{V+I R_{S}}{R_{S h}}
$$

$\mathrm{N}$ The diode ideality factor,

K The Boltzmann's constant,

$T_{c} \quad$ Cell temperature in Kelvin,

q Electronic charge and $=1.6 * 10^{-19}$ Coulomb,

$\mathrm{V}$ Voltage of the cell in Volt,

$I_{0} \quad$ Reverse saturation current at $T_{c}$ temperature,

$I_{\text {sh }} \quad$ Current through parallel resistance,

\section{MEASUREMENT SYSTEM SETUP}

To characterize the performance of photovoltaic panel we should trace its current-voltage (I-V) characteristic, in [5] they have utilized the microcontroller to evaluate the measurement of the solar cell. In [10], [11] they have used the data acquisition (DAC) as platform between the PV cells and LabVIEW application to obtain the performance of the solar cell. In this work (as shown in Fig. 2), the Arduino represents the heart component of the acquisition system.
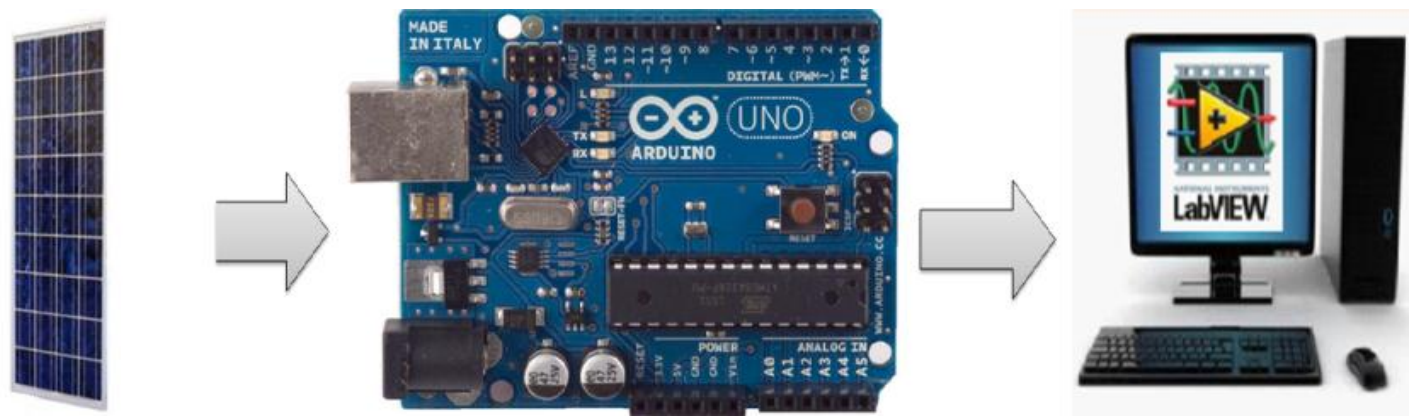

Figure 2. Acquisition system setup

\subsection{Electronic load}

In this work, we setup an acquisition system to measure I-V and P-V curve of PV solar panel as shown in Fig. 3. The Diagram of the electronic circuit tracer illustrates that the circuit uses the MOSFET IRFP064 as a variable resistance to take all the points (current, voltage) of each load value from open circuit voltage to short circuit current of solar panel. With the polarization drain-source voltage (VDS) and the increasing of gate-source voltage (VGS), the current Id provided between drain and source increase also. Therefore, the operating mode of The MOSFET transistor is controlled by VGS voltage. When gate voltage is high than the threshold voltage (Vt), the MOSFET operate in saturation mode $((\mathrm{VGS}-\mathrm{Vt})<\mathrm{VDS})$ as described in Eq. (3), in the case if the voltage issue from the photovoltaic panel is lower, the MOSFET will be in its linear regime $((\mathrm{VGS}-\mathrm{Vt})>\mathrm{VDS})$ as represented in Eq. (4). However, the MOSFET will be in blocked region when VGS is less than Vt.

$$
\begin{aligned}
& I_{d}=K_{N}\left[2\left(V_{G S}-V_{t}\right) V_{D S}-V_{D S}^{2}\right] \\
& I_{d}=K_{N}\left[2\left(V_{G S}-V_{t}\right)\right]
\end{aligned}
$$

Where $K_{N}$ is the device constant 


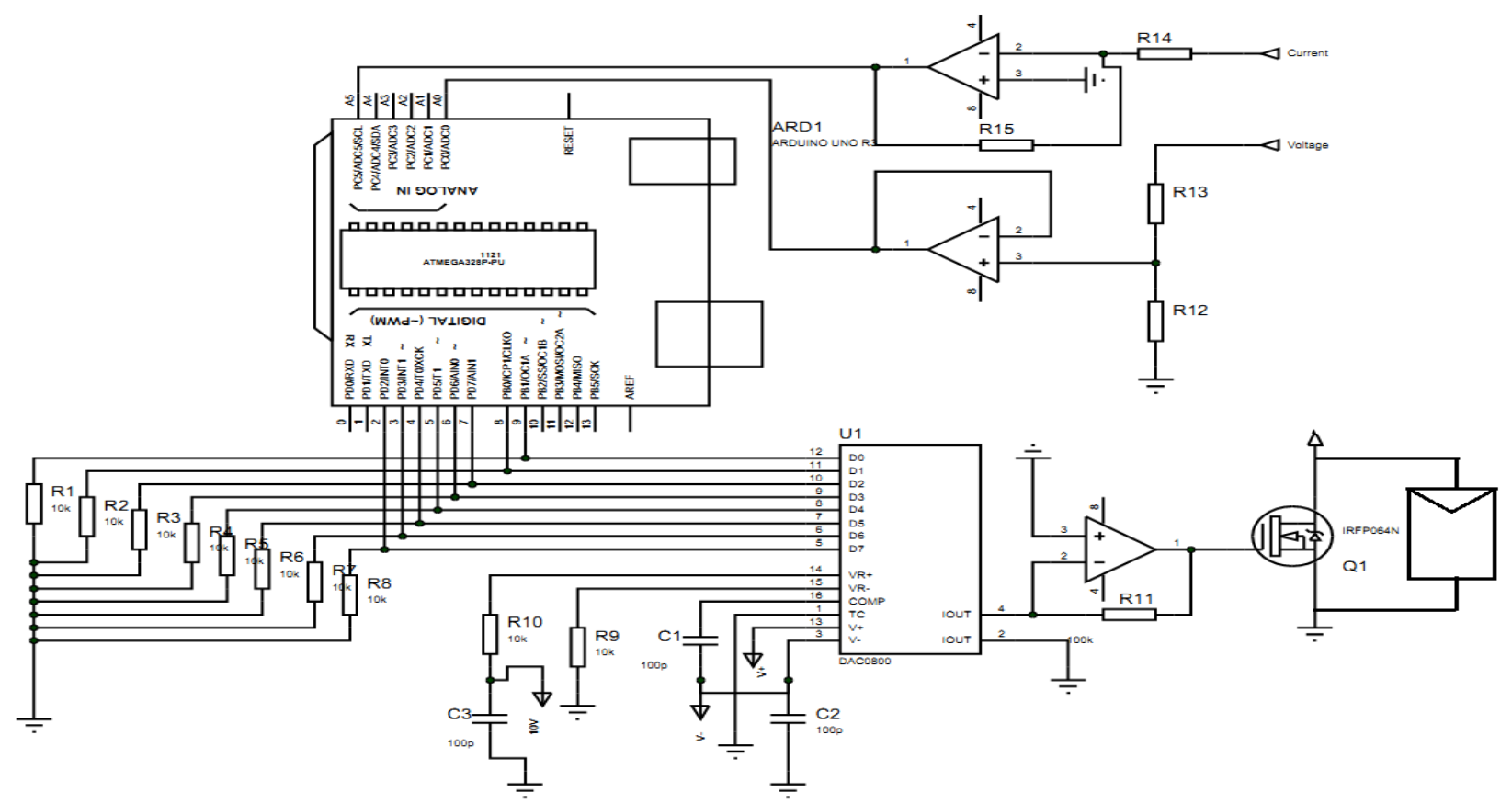

Figure 3. Schematic diagram of electronic circuit

\subsection{Arduino}

The Arduino Uno is a microcontroller board based on the ATmega328. It has 14 digital input/output pins of which 6 can be used as PWM output, 6 analog inputs, a $16 \mathrm{MHz}$ ceramic resonator and a USB connection. It contains everything needed to support the microcontroller; simply connect it to a computer with a USB cable. The ATmega328 has 32 $\mathrm{KB}$ (with $0.5 \mathrm{~KB}$ used for the boot loader), $2 \mathrm{~KB}$ of SRAM and $2 \mathrm{~KB}$ of EEPROM. The Arduino Uno can be powered via the USB connection or with an external power supply [12].

- The Arduino can only generates a numeric signal voltage to feed the gate terminal of the MOSFET. In this case, we need to use a digital-to-analog converter (DAC). The electronic circuit utilizes 8Bit DAC0800; it is 8-bit high-speed current-output digital-to-analog converters, where its terminal output provides a negative current, which be the inverter input of an operational amplifier to convert it to analog voltage.

- With CS100-VP sensor we can measure all solar module output current values of each load resistance, because the operating range of this current sensor is over $100 \mathrm{~A}$, and it has very fast response and high accuracy. Based on principle of Hall Effect, the output terminal of the sensor provides a voltage, which represents the perfect image of the primary (input) current issue from the photovoltaic panel. When the Arduino board senses this output voltage, this last will be transmitted to the computer, then the graphical programming environment LabVIEW makes the necessary transformation.

- To measure the terminal voltage provided by the solar panel, we set up a voltage divider (R12, R13) to minimize the voltage value (because the Arduino board operate in range of positive voltage between $0-5 \mathrm{~V})$, which will be input of non-inverting of operational amplifier to stabilize it.

\section{NI LABVIEW INTERFACE FOR ARDUINO TOOLKIT}

To make an interface between the Arduino microcontroller and Laptop, the NI LabVIEW Interface for Arduino (LIFA) is necessary. With this toolkit and the graphical programming environment LabVIEW, you can control or acquire data from the Arduino microcontroller. A sketch for the Arduino microcontroller acts as an $\mathrm{I} / \mathrm{O}$ engine that interfaces with LabVIEW VIs through a serial connection. This helps you quickly move information from Arduino pins to LabVIEW without adjusting the communication, synchronization, or even a single line of $\mathrm{C}$ code. 


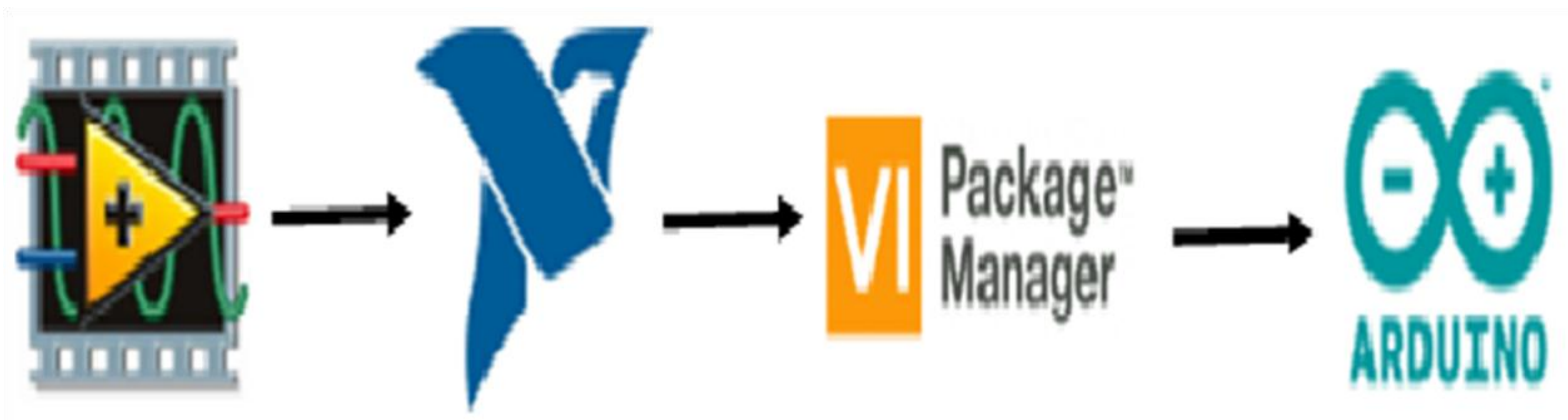

Figure 4. Process of installing LIFA

Using the common Open, Read/Write, Close convention in LabVIEW, you can access the digital, analog, pulse-width-modulated signals of the Arduino microcontroller. To make the interface as shown in Fig. 4 you should install in the computer LabVIEW 2011 or later and NI-VISA, the Arduino IDE is required to build LIFA's open source firmware and also JKI VI Package Manager (VIPM) to provide an easy way to install and update LabVIEW libraries) [12].

\section{PROGRAM FLOW CHART}

Based on ATMEL microcontroller of ATMega328 reference, we can control the open source Arduino as shown in

Fig. 5. After making the necessary initialization, from each given gate-source voltage generated to the load resistance (MOSFET), the measured data generated by the photovoltaic panel can be transferred one by one through a serial communication to the computer.

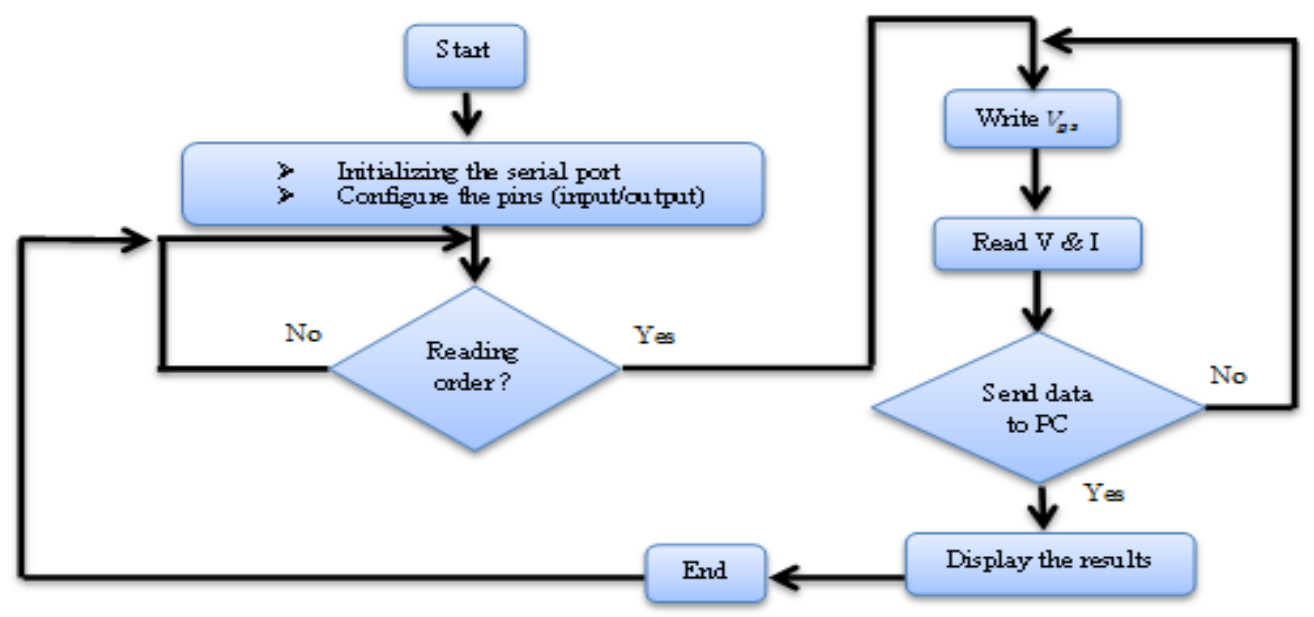

Figure 5. Acquisition system Flow chart

\section{LABVIEW PROGRAM}

The Arduino Uno model can communicate with other microcontroller, computer or another Arduino. The AT mega 328 provides UART TTL (5V) serial communication, which is available on digital pins 0 (RX) and 1 (TX), Instead to program it by the
Arduino software, in this work we use NI LabVIEW Interface Toolkit to integrate the Arduino in the virtual instrumental LabVIEW libraries. The Fig. 6 represents the block diagram of PV panel test system, which utilized to acquire the measured data. The block diagram is divided into four parts, the section one illustrate the initialization of serial visa 
between the hardware and software, and the configuration of 8 pins of the Arduino as output (2-9 pins). The second stage makes order to each selected pin (write), the third stage shows that the current and voltage are carried out via two analogs inputs channels $(0,5$ pins $)$, and finally the results are displayed in computer screen in last section.

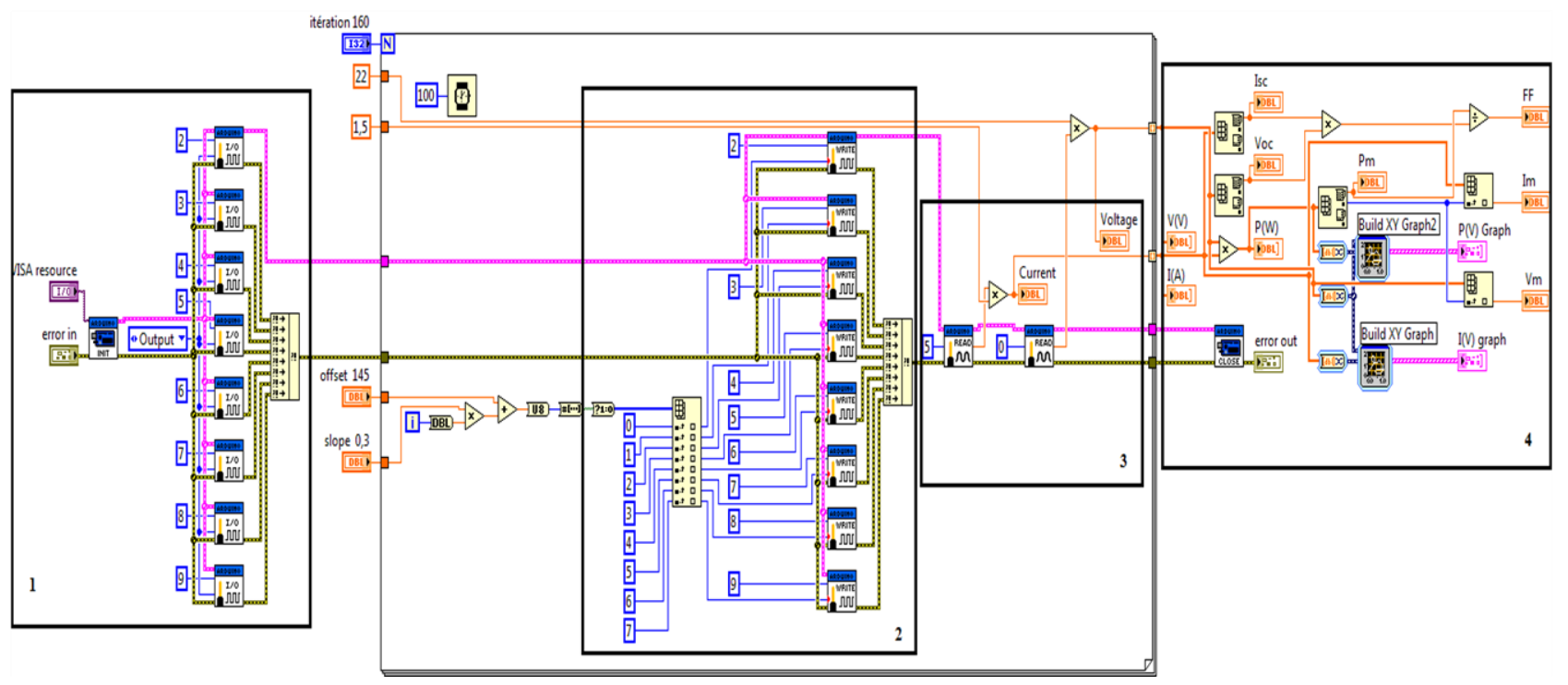

Figure 6. Block diagram of the acquisition system

\section{EXPERIMENTAL RESULTS}

The acquisition system was described previously in measurement system setup section is used together with GUI LabVIEW application software to achieved the current-voltage (I-V) and powervoltage $(\mathrm{P}-\mathrm{V})$ characteristics curves of PWX500 poly-crystalline photovoltaic panel, which contains 36 solar cells (4 inch cells, 101,50 x 101,50 mm). 


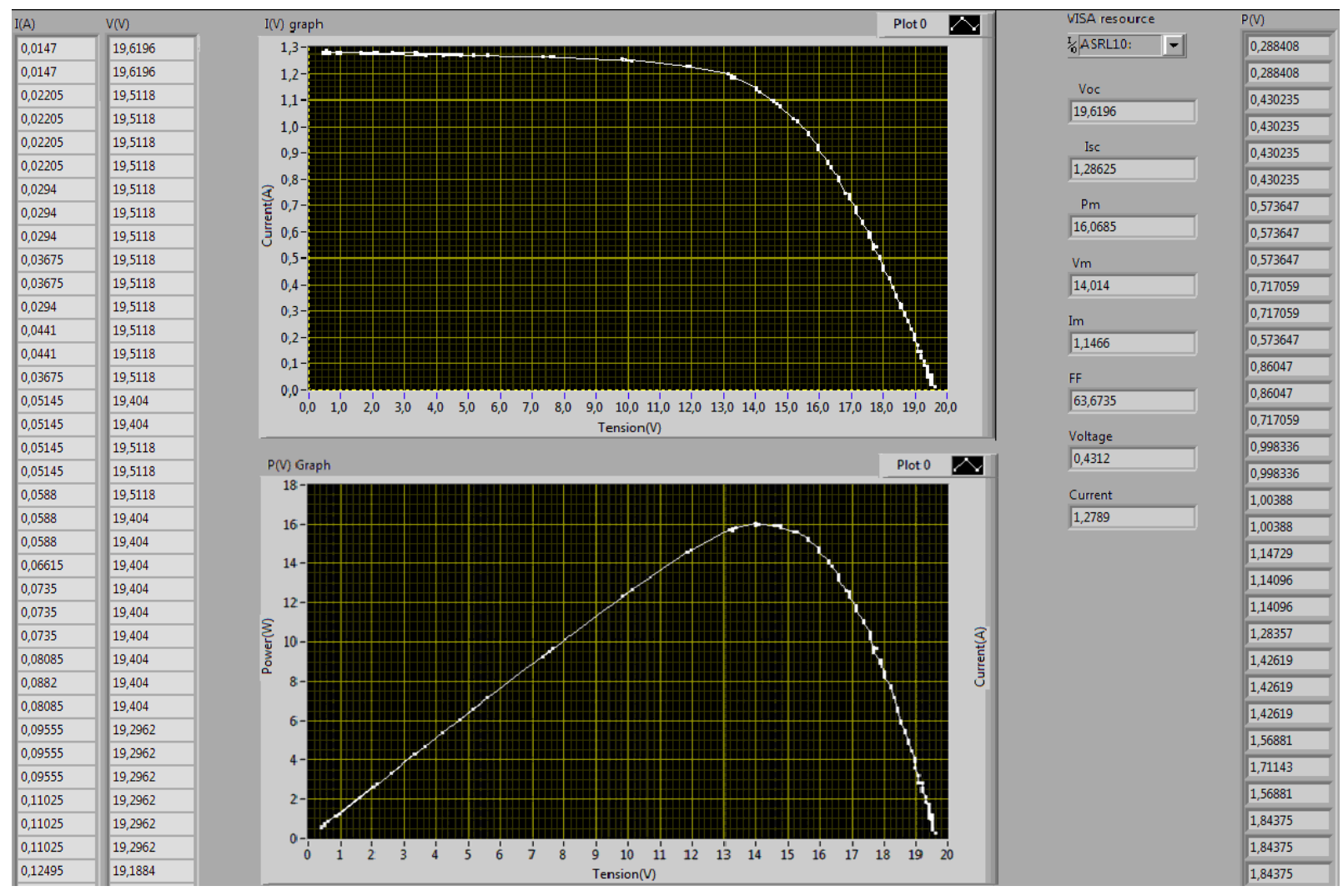

Figure 7. Results front panel of the acquisition system

The results data were received by LabVIEW front panel, are illustrated also in arrays form, in which we have the numeric values of current and voltage, and then the measured power is deduced. The developed system calculates also open-circuit voltage (Voc), short-circuit current (Isc), maximum power point $(\mathrm{Pm}, \mathrm{Im}, \mathrm{Vm})$ and fill factor $(\mathrm{FF})$. The results are displayed in front panel in LabVIEW interface as shown in Fig. 7. The characteristic I-V given in the datasheet of PWX500 and those obtained with the presented electronic circuit are similar, which indicate that the developed LabVIEW programs used in this characterization is valid.

\section{CONCLUSION}

This article describes inside its papers an automated acquisition system, which used to measure the characteristics current versus voltage (I-V) and power versus voltage $(\mathrm{P}-\mathrm{V})$ of a photovoltaic panel, the electronic circuit is implemented to allow the user to extracting the necessary parameters values of the solar module in outdoor conditions. Based on LabVIEW software, the open source Arduino Uno is used in the designed system. The power MOSFET is used as fast variable load controlled by the Arduino. Put into consideration the working range of the MOSFET, the system can utilized to monitoring PV modules or strings.

\section{REFERENCES}

[1] R. Pal, V. K. Sethi, and A. Gour, "Assessing the Performance of $100 \mathrm{~kW}$ Solar PV Power-plants Through I-V Characterization \& Validation of Tilted Irradiance Calculation Compared to an Hourly Model," 2014.

[2] V. Leite and F. Chenlo, "An improved electronic circuit for tracing the IV characteristics of photovoltaic modules and strings," in International Conference on Renewable Energies and Power Quality (ICREPQ'12), 2010.

[3] Vicente Leite, José Batista, Faustino Chenlo and João L. Afonso "Low-Cost Instrument for Tracing Current-Voltage Characteristics of Photovoltaic Modules," in International Conference on Renewable Energies and Power Quality (ICREPQ'12), 2010

[4] E. Duran, M. Piliougine, M. Sidrach-de-Cardona, 
J. Galán, and J. M. Andujar, "Different methods to obtain the I $-\mathrm{V}$ curve of PV modules: A review," in 33rd IEEE Photovoltaic Specialists Conference, 2008.

PVSC '08, 2008, pp. 1-6.

[5] Y. Atia, M. Zahran, and A. Al-Hossain, "Solar Cell Curves Measurement Based on LabVIEW Microcontroller Interfacing," in Proceedings of the 12th WSEAS International Conference on Automatic Control, Modelling and Simulation, Catania, Sicily, Italy May, 2010, pp. 29-31.

[6] U. Zimmermann and M. Edoff, "A Maximum Power Point Tracker for Long-Term Logging of PV Module Performance," IEEE Journal of Photovoltaics, vol. 2, no. 1, pp. 47-55, Jan. 2012.

[7] C. R. Jeevandoss, M. Kumaravel, and V. J. Kumar, "Sunlight based I-V characterization of solar PV cells," in 2011 IEEE Instrumentation and Measurement Technology Conference (I2MTC), 2011, pp. 1-4.

[8] A. Mahrane, A. Guenounou, Z. Smara, M.
Chikh, and M. Lakehal, "Test Bench for Photovoltaic Modules," in International Symposium on Environment Friendly Energies in Electrical Applications, 2010.

[9] V. Nanjannavar, P. Gandhi, and N. Patel, "LabVIEW based PV cell characterization and MPPT under varying temperature and irradiance conditions," in 2013 Nirma University International Conference on Engineering (NUiCONE), 2013, pp. 1-6.

[10] W.-T. Huang, K.-C. Yao, C.-C. Wu, and Y.-H. Huang, "A LABWIEW TM BASED PHOTOVOLTAIC CELLS VIRTUAL INSTRUMENTAL SYSTEM FOR EDUCATIONAL PURPOSE," Electronic Products, vol. 11, p. 14.

[11] A. Sahbel, N. Hassan, M. M. Abdelhameed, and A. Zekry, "Experimental Performance Characterization of Photovoltaic Modules Using DAQ," Energy Procedia, vol. 36, pp. 323-332, 2013.

[12] Internet: http://www.ni.com. 